\section{Ruptured intracranial dermoid}

A 48-year-old man presented with sudden-onset headache and vomiting for $6 \mathrm{~h}$ and altered sensorium for $2 \mathrm{~h}$. He was febrile with tachycardia, neck rigidity and positive Kernig's sign. Cerebrospinal fluid examination showed neutrophilic pleocytosis, raised protein and low glucose. Non-contrast CT revealed a large, well-circumscribed hypodense mass measuring $5 \times 3 \mathrm{~cm}$ involving the right frontobasal area with subtle peripheral calcification. The mean attenuation value of the hypodense area measured 87 Hounsfield units. MRI was performed to characterise the mass further (figs 1, 2).

On Tl-weighted images (TR/TE 450/ $20)$, the mass appeared brightly hyperintense with a few hypointense areas

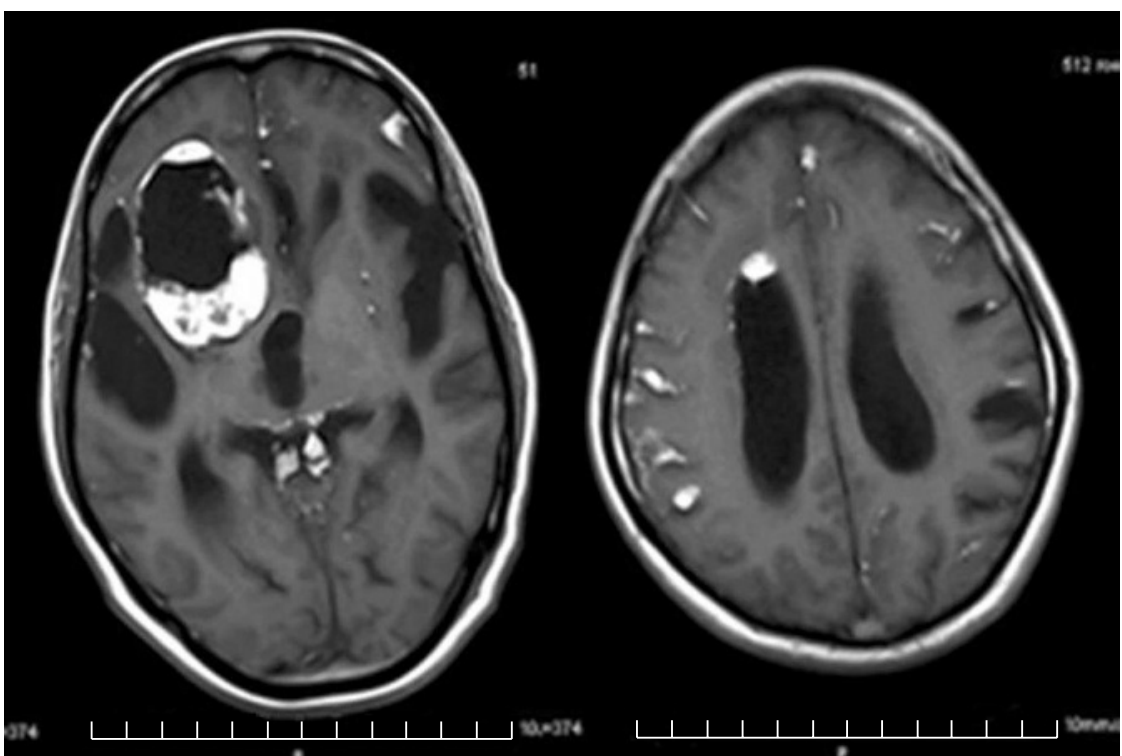

Figure $1 \mathrm{Tl}$-weighted (TR/TE, 450/20) axial image showing a hyperintense soft tissue mass in the right frontobasal region with brightly hyperintense foci in the quadrigeminal cistern and subarachnoid space. Axial section at a higher level showing the presence of multiple hyperintense areas in the sulci and in the right lateral ventricle.

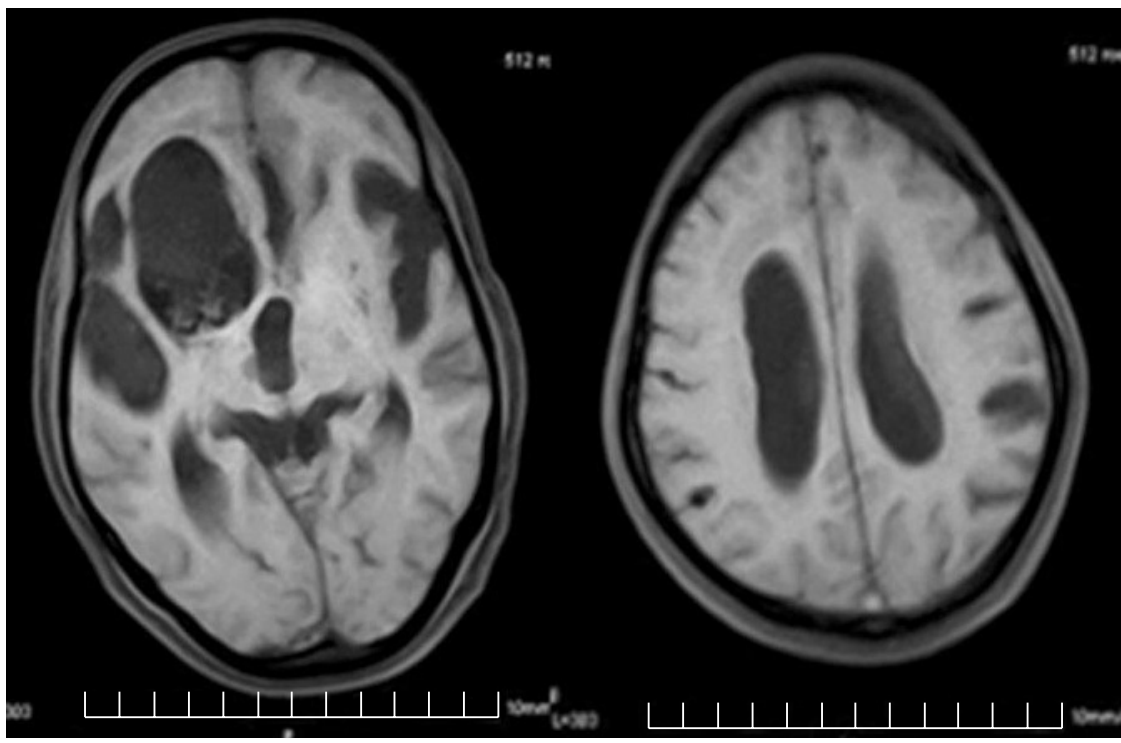

Figure 2 T1-weighted (TR/TE, 450/20) fat-saturated axial image at same levels showing uniform suppression of the hyperintense foci, confirming the presence of fat in these areas. within. Multiple hyperintense foci were also noted in the right lateral ventricle, and in the sulcal and cisternal spaces (fig 1). On fat-suppressed Tl-weighted images, uniform loss of signal intensity of the mass was seen, confirming its fatty nature. Moreover, the bright areas in the sulcal and cisternal spaces as well as in the right ventricle showed signal drop, suggesting the presence of fat in these areas as well (fig 2). On T2-weighted images (TR/TE 4500/80), the mass appeared heterogeneously hyperintense. On the basis of the imaging findings, diagnosis of ruptured dermoid with intraventricular and subarachnoid dissemination of its fatty contents was suggested. The imaging findings were confirmed at surgery and histopathology.

Intracranial dermoid cysts are rare, benign, slow-growing congenital neoplasms and are believed to arise from ectopic ectodermal cell rests incorporated in the neural groove at the time of closure. $^{12}$ They account for $0.04-0.6 \%$ of all primary intracranial neoplasms, ${ }^{3}$ and are commonly seen in the posterior fossa, usually in the midline. Supratentorial dermoid cysts are distinctly uncommon, often seen in parasagittal locations near the skull base. Rarely, they originate from suprasellar and parasellar regions, cavernous sinus, sylvian fissure and pineal gland. ${ }^{4}$

Intracranial dermoid cysts are generally benign tumours and grow slowly by epithelial desquamation and glandular secretion. Symptoms are insidious and non-specific, commonly due to local mass effect resulting in focal neurological dysfunction or obstruction of the cerebrospinal fluid pathway. Clinical features depend on their location, seizure and headache being the most common with uncomplicated supratentorial dermoid cysts. $^{3}$

Intracranial dermoid cysts are known to cause single or multiple episodes of chemical meningitis with or without neurological symptoms, owing to spillage of their contents. A dermoid cyst typically contains variable amounts of fat, hair and sebaceous secretions, which determine their imaging features. Rupture of an intracranial dermoid cyst, although rare, occurs mostly spontaneously but may be iatrogenic during surgery or after closed head injury. ${ }^{5}{ }^{6}$ It can lead to potentially serious and fatal complications. Asymptomatic spontaneous rupture of intracranial dermoid cyst has been described. ${ }^{4}$ In one study of patients with 
ruptured intracranial dermoid, headache and seizures were most common, followed by temporary sensory/motor disturbances. Chemical meningitis was found in only $7 \%$ of patients.

Before the CT/MRI era, diagnosis of chemical meningitis was rather elusive. However, with the advent of newer imaging techniques, cases of mild subacute forms of this disease are being increasingly recognised.

Chandan Jyoti Das Department of Radiodiagnosis, All India Institute of Medical Sciences, New Delhi, India

Mohammad Tahir Department of Medicine, All India Institute of Medical Sciences, New Delhi, India
Jyotindu Debnath

Department of Radiodiagnosis, All India Institute of Medical Sciences, New Delhi, India

Ghan Shyam Pangtey

Department of Medicine, All India Institute of Medical Sciences, New Delhi, India

Correspondence to: Dr C J Das, Department of Radiodiagnosis, All India Institute of Medical Sciences, New Delhi 110029, India; dascj@yahoo.com

Competing interests: None declared.

\section{References}

1 Stendel R, Pietila TA, Lehmann K, et al. Ruptured intracranial dermoid cysts. Surg Neurol 2002;57:391-8.
2 Atlas AW, Lavi E, Goldberg HI. Extraaxial brain tumors. In: Atlas AW, eds. Magnetic resonance imaging of the brain and spine, 3rd edn. Philadelphia: Lippincott Williams \& Wilkins, 2002:695-772.

3 Lunardi P, Missori P. Supratentorial dermoid cysts. J Neurosurg 1991;75:262-6.

4 Venkatesh SK, Phadke RV, Trivedi P, et al. Asymptomatic spontaneous rupture of suprasellar dermoid cyst: a case report. Neurol India 2002;50:480-3.

5 Phillips WE II, Martinez CR, Cahill DW. Ruptured intracranial dermoid tumor secondary to closed head trauma. Computed tomography and magnetic resonance imaging. J Neuroimaging 1994;4:169-70.

6 Carvalho GA, Cervio A, Matthies C, et al. Subarachnoid fat dissemination after resection of a cerebellopontine angle dysontogenic cyst: case report and review of the literature. Neurosurgery 2000;47:760-3.

7 Funk M. Ruptured intracranial dermoid as an incidental finding. Aktuelle Radiol 1995;5:232-4.

\section{Save your favourite articles and useful searches}

Use the "My folders" feature to save and organise articles you want to return to quickly-saving space on your hard drive. You can also save searches, which will save you time. You will only need to register once for this service, which can be used for this journal or all BMJ Journals, including the BMJ. 